Disclosure of Interest: L. Berkhout: None declared, J. Ruwaard: None declared, M. I'Ami: None declared, G. Wolbink Grant/research support from: Pfizer, Speakers bureau: Pfizer, UCB, AbbVie, Biogen, BMS, T. Rispens Grant/research support from: Genmab, Speakers bureau: Pfizer, AbbVie, Regeneron DOI: 10.1136/annrheumdis-2018-eular.5419

\section{FRI0126 PATIENTS' CONCERNS ABOUT AND PERCEPTION OF BIOSIMILARS IN RHEUMATOLOGY : A FRENCH SURVEY}

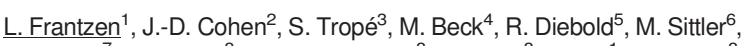
A. Munos $^{7}$, L. Arnaud ${ }^{8}$, J.-E. Gottenberg ${ }^{8}$, J. Sibilia ${ }^{8}$, N. Afif $^{1}$, C. Sordet ${ }^{8}$ on behalf of CERBER : Comité d'Etudes et de Réflexion sur les Biosimilaires en Rhumatologie. ' Service de Rhumatologie, GHR Mulhouse Sud Alsace, Mulhouse; ${ }^{2}$ Service de rhumatologie, Centre Hospitalier Universitaire de Montpellier, ${ }^{3}$ ANDAR, Montpellier, ${ }^{4}$ Agence Régionale de Santé; ${ }^{5}$ Service de Rhumatologie, Association France Spondylarthrite; ${ }^{6}$ Hôpitaux Universitaires de Strasbourg, Strasbourg; ${ }^{7}$ Université de Tours, Tours; ${ }^{8}$ Service de Rhumatologie, Hôpitaux Universitaires de Strasbourg, Strasbourg, France

Background: Patient adhesion to biosimilars DMARDs have become a big medico-economic issue. Indeed, savings will depend on penetration rate of biosimilars on the biologics market. Like generics, biosimilars are unknown by the general population and patients reluctance appears to be an obstacle to the diffusion of these therapeutics.

Objectives: To assess patients'knowledge, information and concerns about biosimilars and to identify levers and obstacles to adhesion to biosimilars prescription.

Methods: National cross-sectional study assessing information, knowledge and concerns about biosimilars of french patients treated for a rheumatism (whether they were treated by a bDMARDs or not). The data were collected from march to july 2017 by an online assessment.

Results: 629 patients answered the assessment. $43 \%$ knew the definition of biosimilars. $65 \%$ felt unsufficiently informed about biosimilars. The principal sources of information were the rheumatologist and the patient associations. $44 \%$ of patients treated with a biosimilar were not informed before they received a biosimilar. Patients concerns focused on molecular structure (46\%), efficacy (60\%) and tolerance (57\%) comparatively to originator bDMARDs.

Receiving information about biosimilars and understanding the definition of biosimilarity were two characteristics associated with better adhesion to biosimilars. The rheumatologist was considered the most influent source of information about biosimilar. Patients trust him concerning the decision to switch from the originator biologic to its biosimilar. Patient were reluctant to substitution by the pharmacist (2\%).

Conclusions: Biosimilars are largely unknown by french patients at present. Information seems to be instrumental in patient adhesion to biosimilars and in the preservation of the therapeutic relationship.

\section{REFERENCES:}

[1] Jacobs I, Singh E, Sewell L, Al-Sabbagh A, Shane LG. Patient attitudes and understanding about biosimilars: an international cross-sectional survey. Patient Prefer Adherence. MAI 2016;937

[2] Beck M, Michel B, Rybarczyk-Vigouret M-C, Levêque D, Sordet C, Sibilia J, et al. Rheumatologists' Perceptions of Biosimilar Medicines Prescription: Findings from a French Web-Based Survey. BioDrugs Clin Immunother Biopharm Gene Ther. Déc 2016;30(6):585-92.

Disclosure of Interest: None declared

DOI: 10.1136/annrheumdis-2018-eular.4888

\section{FRI0127 OPEN-LABEL NON-MANDATORY TRANSITIONING FROM ORIGINATOR ETANERCEPT TO BIOSIMILAR SB4: 6-MONTH RESULTS FROM A CONTROLLED COHORT STUDY}

L. Tweehuysen ${ }^{1}$, V.J.B. Huiskes ${ }^{2}$, B.J.F. van den Bemt ${ }^{2,3}$, J.E. Vriezekolk ${ }^{1}$, S. Teerenstra ${ }^{4}$, F.H.J. van den Hoogen ${ }^{1,5}$, C.H. van den Ende ${ }^{1,5}$, A.A. den Broeder ${ }^{1,5} .{ }^{1}$ Rheumatology; ${ }^{2}$ Pharmacy, Sint Maartenskliniek; ${ }^{3}$ Pharmacy; ${ }^{4}$ Radboud Institute for Health Sciences, department for Health Evidence; ${ }^{5}$ Rheumatology, Radboud University Medical Center, Nijmegen, Netherlands

Background: Open-label mandatory transitioning to a biosimilar has no impact on disease activity in inflammatory rheumatic diseases. ${ }^{1}$ In light of shared treatment decision-making between patients and physicians, non-mandatory transitioning might be preferable above mandatory transitioning. First attempts with non-mandatory transitioning unfortunately showed suboptimal acceptance and persistence rates to a biosimilar. ${ }^{2}$
Objectives: To evaluate the effects of non-mandatory transitioning from originator etanercept (ENB) to biosimilar etanercept (SB4) on drug survival and effectiveness in a controlled cohort study of patients with an inflammatory rheumatic disease.

Methods: In 2016, 642 ENB treated patients were asked to transition to SB4 by a structured communication strategy with opt-out option. Consenting patients were eligible for the current study [BIO-SPAN]. ENB treated patients in 2014 were recruited as historical cohort. Drug survival was compared by Cox regression analyses adjusting for age, gender, diagnosis, ENB treatment duration, ENB dose interval, csDMARD and CRP, using a robust variance estimator to account for repeated subjects. Adjusted differences in CRP, DAS28-CRP and BASDA change over 6 months were assessed.

Results: 635 (99\%) patients agreed to transition to SB4 of whom 625 patients (433 RA, 128 PsA, 64 axSpA) were included in the transition cohort. Additionally 600 patients were included in the historical cohort. Crude 6 months retention rates of SB4 in the transition cohort and ENB in the historical cohort were: $90 \%(95 \% \mathrm{Cl}$ $88 \%-93 \%)$ vs $92 \%(95 \% \mathrm{Cl} 90 \%-94 \%)$. The transition cohort had a significantly higher relative risk of discontinuation (adjusted $\mathrm{HR} 1.57,95 \% \mathrm{Cl} 1.05-2.36$ ). Reasons for discontinuing SB4 $(n=60)$ and ENB $(n=46)$ were: lack of effect $(43 \%$ vs $61 \%$ ), adverse events ( $47 \%$ vs $28 \%$ ), malignancy ( $3 \%$ vs $4 \%$ ), pregnancy ( $4 \%$ vs $4 \%$ ), other (3\% vs $3 \%$ ). In the transition cohort, 17 patients restarted ENB, 32 patients switched to another biologic and 11 patients maintained biologic-free. DAS28-CRP, BASDAI and CRP were similar between baseline and month 6 . Compared with the historical cohort, the transition cohort had a smaller decrease in CRP (adjusted diff $1.8(95 \% \mathrm{Cl} 0.3-3.2))$ and DAS28-CRP (adjusted diff 0.15 (95\% Cl 0.05-0.25)) over 6 months.

Conclusions: Open-label non-mandatory transitioning from ENB to SB4 using a structured communication strategy showed a slightly lower persistence rate and smaller decreases in disease activity compared with a historical cohort, but these differences were considered as not being clinically relevant. The acceptance and persistence rates of SB4 in our transition cohort were similar to those of mandatory transitioning. Since mandatory transitioning is not acceptable in many countries, the use of a communication strategy which might optimise acceptance and persistence rates of non-mandatory transitioning seems attractive.

\section{REFERENCES:}

[1] Glintborg B, et al. Ann Rheum Dis 2017.

[2] Tweehuysen L, et al. Arthritis Rheumatol 2017.

Disclosure of Interest: L. Tweehuysen: None declared, V. J. Huiskes: None declared, B. J. van den Bemt Speakers bureau: Pfizer, Abbvie, Sandoz, UCB, J. Vriezekolk: None declared, S. Teerenstra: None declared, F. H. van den Hoogen Consultant for: Celltrion, Sandoz, Mundipharma, Biogen, Speakers bureau: Cellt rion, Sandoz, Janssen, Egis, C. van den Ende: None declared, A. den Broeder Grant/research support from: CZ, Menzis, ZonMw, Consultant for: Amgen, Boehringer Ingelheim, Speakers bureau: Bristol-Myers Squibb, Pfizer DOI: 10.1136/annrheumdis-2018-eular.2592

\section{FRI0128 INTEGRATED SAFETY DATA ANALYSIS ACROSS PHASE 3 CLINICAL STUDIES FOR INTRAVENOUS GOLIMUMAB IN RHEUMATOID ARTHRITIS, PSORIATIC ARTHRITIS, AND ANKYLOSING SPONDYLITIS}

M.E. Husni ${ }^{1}$, S. Schwartzman ${ }^{2}$, A. Deodhar ${ }^{3}$, S. Kafka ${ }^{4}$, S.D. Chakravarty ${ }^{5}$, E. C. Hsia ${ }^{6}$, D.D. Harrison' ${ }^{7}$, J.H. Leu ${ }^{8}$, Y. Zhou ${ }^{8}$, K.H. Lo ${ }^{8}$, A. Kavanaugh ${ }^{9} .{ }^{1}$ Cleveland Clinic, Cleveland; ${ }^{2}$ Weill Cornell Medical College, New York, ${ }^{3}$ Oregon Health and Science U, Portland; ${ }^{4}$ Janssen Scientific Affairs, LLC; ${ }^{5}$ Janssen Scientific Affairs, LLC/Drexel U College of Med, Horsham; ${ }^{6}$ Janssen Research and Development, LLC/U Penn, Spring House/Phila; 7 Janssen Research and Development, LLC, Horsham; ${ }^{8}$ Janssen Research and Development, LLC, Spring House; ${ }^{9}$ UCSD, San Diego, USA

Background: Intravenous golimumab (IV GLM) is approved for treatment of adults w/rheumatoid arthritis (RA), psoriatic arthritis (PsA) and ankylosing spondylitis (AS).

Objectives: To present the integrated safety data from three Phase 3 studies of IV GLM in patients (pts) w/RA, PsA and AS up to 24 weeks (wks). Safety outcomes in pts receiving concomitant methotrexate (MTX) and low-dose oral corticosteroids (CS) were assessed when used in treatment of the indicated disease. Methods: Integrated safety data from Phase 3 double-blind placebo-controlled trials (RA [GO-FURTHER], PsA [GO-VIBRANT] and AS [GO-ALIVE]) were analysed up to wk24. In general, pts received either IV PBO or IV GLM (2 mg/kg) at 0 , 4,12 , and 20 wks. PBO pts crossed over to GLM at wk24 except RA pts randomised to PBO who met early escape criteria crossed over at wk16 and AS pts randomised to $\mathrm{PBO}$, who crossed-over at wk16. Data before crossover are presented. Infusion reactions, infections, serious infections, serious adverse events (SAEs), death, and antidrug antibodies (ADAs) were evaluated. 
Results: Overall, 740 and 539 pts were randomised to IV GLM and PBO groups, respectively. The\% of IV GLM vs PBO pts reported the following across studies: infusion reactions ( 2.8 vs 0.2 ); SAEs ( 3.8 vs 2.4 ); infections ( 23.8 vs 17.3 ); serious infections (0.8 vs 0.4$)$ and malignancies ( 0.1 vs 0.4$)$. No deaths occurred in IV GLM group through wk24. Pts on IV GLM $(n=574)$ vs PBO $(n=391)$ w/concomitant MTX had similar proportions of serious infections ( 0.9 vs. 0.6$)$. In IV GLM ( $n=349)$ vs PBO $(n=224)$ pts who received CS, serious infections were $1.1 \%$ vs $0.9 \%$; in pts who did not receive CS, serious infections were $0.5 \%$ vs $0 \%$. In IV GLM pts w/ normal ALT at baseline, $30 \%$ had postbaseline ALT elevation w/concomitant MTX vs $28 \%$ w/o. CS use had inconsistent effect on ALT elevations. Overall incidence of ADAs via drug tolerant assay was $20 \%$ (19\% w/ MTX and $25 \% \mathrm{w} / \mathrm{o}$ MTX) through wk20 across RA, PsA and AS studies.

\begin{tabular}{|c|c|c|c|c|c|c|c|c|}
\hline & \multicolumn{2}{|c|}{ RA } & \multicolumn{2}{|c|}{ PsA } & \multicolumn{2}{|c|}{ AS } & \multicolumn{2}{|c|}{ ALL } \\
\hline & $\begin{array}{l}\mathrm{IV} \\
\text { GLM }\end{array}$ & PBO & $\begin{array}{c}\text { IV } \\
\text { GLM }\end{array}$ & PBO & $\begin{array}{c}\text { IV } \\
\text { GLM }\end{array}$ & PBO & $\begin{array}{c}\text { IV } \\
\text { GLM }\end{array}$ & $\overline{\mathrm{PBO}}$ \\
\hline Treated Pts & 395 & 197 & 240 & 239 & 105 & 103 & 740 & 539 \\
\hline $\begin{array}{l}\text { Age in years, Mean } \\
\text { (Range) }\end{array}$ & $\begin{array}{r}51.9 \\
\left({ }^{18-83}\right.\end{array}$ & $\begin{array}{r}51.4 \\
\left({ }^{19-78}\right.\end{array}$ & $\begin{array}{r}45.7 \\
\left({ }^{19-69}\right.\end{array}$ & $\begin{array}{r}46.7 \\
\left({ }^{18-79}\right.\end{array}$ & $\begin{array}{r}38.4 \\
\left({ }^{19-64}\right.\end{array}$ & $\begin{array}{r}39.2 \\
(20-67\end{array}$ & & \\
\hline $\begin{array}{l}\text { Disease Duration in } \\
\text { Years, Mean (SD) }\end{array}$ & $\begin{array}{c}6.9 \\
(7.00)\end{array}$ & $\begin{array}{c}7.0 \\
(7.24)\end{array}$ & $\begin{array}{c}6.2 \\
(6.03)\end{array}$ & $\begin{array}{c}5.3 \\
(5.92)\end{array}$ & $\begin{array}{c}5.6 \\
(6.57)\end{array}$ & $\begin{array}{c}5.5 \\
(5.93)\end{array}$ & & \\
\hline $\begin{array}{l}\text { Avg duration of } \\
\text { follow-up (wks) }\end{array}$ & 23.6 & 20.9 & 23.9 & 23.2 & 16.1 & 16.0 & 22.6 & 21.0 \\
\hline $\begin{array}{l}\text { Pts } w / \geq 1 \text { infusion } \\
\text { reaction, } \\
n(\%)\end{array}$ & $\begin{array}{c}14 \\
(3.5)\end{array}$ & $1(0.5)$ & $4(1.7)$ & 0 & $3(2.9)$ & 0 & $\begin{array}{c}21 \\
(2.8)\end{array}$ & $1(0.2)$ \\
\hline $\begin{array}{l}\mathrm{Pts} w / \geq 1 \mathrm{SAE}, \\
\mathrm{n}(\%)\end{array}$ & $\begin{array}{c}19 \\
(4.8)\end{array}$ & $5(2.5)$ & $7(2.9)$ & $8(3.3)$ & $2(1.9)$ & 0 & $\begin{array}{c}28 \\
(3.8)\end{array}$ & $\begin{array}{c}13 \\
(2.4)\end{array}$ \\
\hline $\begin{array}{l}\text { Pts } w / \geq 1 \text { infection, } n \\
(\%)\end{array}$ & $\begin{array}{c}119 \\
(30.1)\end{array}$ & $\begin{array}{c}48 \\
(24.4)\end{array}$ & $\begin{array}{c}45 \\
(18.8)\end{array}$ & $\begin{array}{c}37 \\
(15.5)\end{array}$ & $\begin{array}{c}12 \\
(11.4)\end{array}$ & $8(7.8)$ & $\begin{array}{c}176 \\
(23.8)\end{array}$ & $\begin{array}{c}93 \\
(17.3)\end{array}$ \\
\hline $\begin{array}{l}\text { Pts } w / \geq 1 \text { serious } \\
\text { infection, } n(\%)\end{array}$ & $4(1.0)$ & 0 & $1(0.4)$ & $2(0.8)$ & $1(1.0)$ & 0 & $6(0.8)$ & $2(0.4)$ \\
\hline $\begin{array}{l}\text { Pts } w / \geq 1 \text { malignancy, } \\
n(\%)\end{array}$ & $1(0.3)$ & 0 & 0 & $2(0.8)$ & 0 & 0 & $1(0.1)$ & $2(0.4)$ \\
\hline Deaths, n (\%) & 0 & $1(0.5)$ & 0 & $2(0.8)$ & 0 & 0 & 0 & $3(0.6)$ \\
\hline$\%$ ADA positive* & 21 & & 20 & & 19 & & 20 & \\
\hline
\end{tabular}

${ }^{*}$ w/drug tolerant assay

Conclusions: IV GLM demonstrates the expected safety profile across RA, PSA and AS clinical trials in the PBO-controlled period. Differences between studies may be related to age, use of concomitant medications and disease indication. Disclosure of Interest: M. Husni: None declared, S. Schwartzman: None declared, A. Deodhar: None declared, S. Kafka Employee of: Janssen Scientific Affairs, LLC, S. Chakravarty: None declared, E. Hsia: None declared, D. Harrison: None declared, J. Leu: None declared, Y. Zhou: None declared, K. Lo: None declared, A. Kavanaugh: None declared

DOI: 10.1136/annrheumdis-2018-eular.5425

\section{FRI0129 SWITCH BETWEEN REFERENCE ETANERCEPT (ETN) AND GP2015, AN ETANERCEPT BIOSIMILAR, DID NOT IMPACT EFFICACY AND SAFETY IN PATIENTS WITH MODERATE-TO-SEVERE RHEUMATOID ARTHRITIS: 48- WEEK RESULTS FROM THE PHASE 3 EQUIRA STUDY}

M. Matucci-Cerinic ${ }^{1}$, H. Schulze-Koops ${ }^{2}$, M. Buch ${ }^{3}$, A. Kavanaugh ${ }^{4}$, Y. Allanore ${ }^{5}$, E.J. Kucharz ${ }^{6}$, G. Babic ${ }^{7} .{ }^{1}$ University of Florence, Florence, Italy; ${ }^{2}$ LudwigMaximilians-University, Munich, Germany; ${ }^{3}$ University of Leeds, Leeds, UK; ${ }^{4}$ UC San Diego School of Medicine, La Jolla, California, USA; ${ }^{5}$ Cochin Hospital, Paris Descartes University, Paris, France; ${ }^{6}$ Medical University of Silesia, Katowice, Poland; ${ }^{7}$ Hexal AG, a Sandoz company, Holzkirchen, Germany

Background: GP2015 is an etanercept biosimilar. It has shown an equivalent efficacy, and comparable safety and immunogenicity to ETN in patients with chronic plaque-type psoriasis. ${ }^{1}$

Objectives: To compare the efficacy and safety of GP2015 versus ETN in patients with moderate-to-severe rheumatoid arthritis (RA) and evaluate the effects of switching from ETN to GP2015.

Methods: EQUIRA was a 48 week, randomised, double-blind, Phase 3 study. The primary endpoint was equivalent change from baseline (BL) in DAS28-CRP at Week 24. Patients $\geq 18$ years with active RA ACR 1987 or ACR/ $/{ }^{\text {EULAR }} 2010$ criteria for $>6$ months before $B L$ and active disease defined as DAS28-CRP $>3.2$ and CRP $>5 \mathrm{mg} / \mathrm{L}$ or $\mathrm{ESR} \geq 28 \mathrm{~mm} / \mathrm{h}$ ) and inadequate response to methotrexate (MTX) were randomised $1: 1$ to $50 \mathrm{mg}$ GP2015 or ETN subcutaneously once weekly for 24 weeks (Treatment period 1). Patients with at least moderate EULAR response at Week 24 either continued GP2015 treatment or, in the ETN group, were switched to receive $50 \mathrm{mg}$ GP2015 up to 48 weeks (Treatment period 2 [TP2]). All patients continued to receive concomitant MTX (10-25 mg/week) at a stable dose and folic acid. Efficacy outcome measures included change in DAS28-CRP, EULAR and ACR20/50/70 responses.
Results: Baseline characteristics were comparable between the GP2015 $(n=186)$ and ETN $(n=190)$ groups. The primary endpoint for equivalence was met. $^{2}$ The mean change in DAS28-CRP from BL to Week 48 was comparable between the continued and switched to GP2015 groups (TP2 per-protocol set; figure 1). At Week 48, the EULAR and ACR 20/50/70 response rates were comparable between the two groups (table 1). In TP2, treatment-emergent adverse events (AEs) occurred in $42.9 \%$ vs $38.0 \%$ patients in the continued GP2015 ( $n=175)$ vs the switched $(n=166)$ groups; serious AEs occurred in $2.3 \%$ vs $2.4 \%$ patients (TP2 safety set). Injection site reactions occurred in $6(3.6 \%)$ patients in the switched group but none in the continued GP2015 group. In TP2, 4 (2.4\%) patients in the continued GP2015 group had single-event, very low titer, non-neu tralising antidrug antibodies detected.

Abstract FRI0129 - Table 1. Efficacy response over 48 weeks, TP2 per-protocol set (W=week)

\begin{tabular}{lccc}
\hline Variables & Time & $\begin{array}{c}\text { Continued } \\
\text { GP2015 } \\
\mathbf{n}=148\end{array}$ & $\begin{array}{c}\text { Switched to } \\
\text { GP2015 } \\
\mathbf{n}=131\end{array}$ \\
\hline $\begin{array}{l}\text { EULAR good response, } \mathrm{n}(\%) \\
\text { EULAR moderate response, } \mathrm{n}\end{array}$ & W48 & $80(54.4)$ & $67(51.9)$ \\
$(\%)$ & W48 & $61(41.5)$ & $57(44.2)$ \\
ACR20 response, $\mathrm{n}(\%)$ & W4 & $70(47.9)$ & $70(53.8)$ \\
& W12 & $114(78.1)$ & $100(76.9)$ \\
& W24 & $132(89.8)$ & $122(93.1)$ \\
& W36 & $128(87.7)$ & $114(87.0)$ \\
ACR50 response, $\mathrm{n}(\%)$ & W48 & $131(89.1)$ & $108(82.4)$ \\
& W4 & $19(13.0)$ & $26(20.0)$ \\
& W12 & $48(32.9)$ & $61(46.9)$ \\
& W24 & $93(63.3)$ & $96(73.3)$ \\
ACR70 response, $\mathrm{n}(\%)$ & W36 & $90(61.6)$ & $83(63.4)$ \\
& W48 & $93(63.3)$ & $86(65.6)$ \\
& W4 & $6(4.1)$ & $6(4.6)$ \\
& W12 & $18(12.3)$ & $24(18.5)$ \\
& W24 & $50(34.0)$ & $60(45.8)$ \\
& W36 & $47(32.2)$ & $50(38.2)$ \\
& W48 & $54(36.7)$ & $55(42.0)$ \\
\hline
\end{tabular}

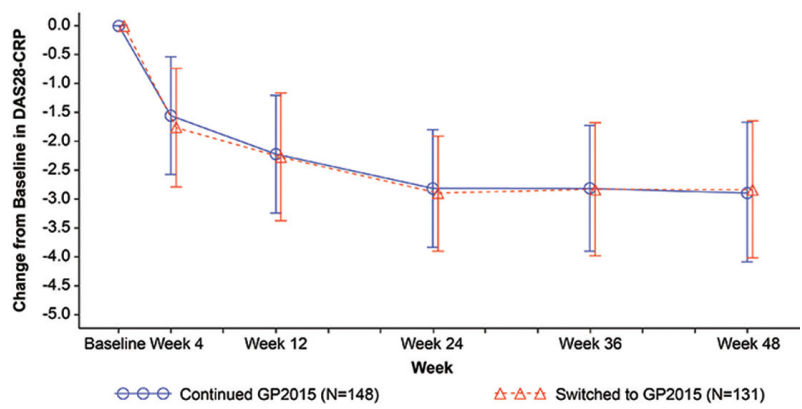

Abstract FRI0129 - Figure 1. Change from Baseline in DAS28-CRP up to Week 48 (TP2 per-protocol set)

Conclusions: The efficacy of GP2015 was comparable to that of ETN. Moreover, the switch from ETN to GP2015 did not impact on efficacy and safety of etanercept in patients with moderate-to-severe RA

\section{REFERENCES}

[1] Griffiths CEM, et al. Br J Dermatol 2017;176:928-38.

[2] Kavanaugh A, et al. Arthritis Rheumatol 2017;69(suppl 10).

Disclosure of Interest: M. Matucci-Cerinic Grant/research support from: Actelion, Beyer, BMS, Chemomab, Inventiva, Pfizer and Sandoz, H. Schulze-Koops: None declared, M. Buch Grant/research support from: Abbvie, AstraZeneca, El Lilly, Pfizer, Roche, Sandoz and UCB, Consultant for: Abbvie, AstraZeneca, Eli Lilly, Pfizer, Roche, Sandoz and UCB, A. Kavanaugh Consultant for: Sandoz, Merck and Boehringer-Ingelheim, Y. Allanore Grant/research support from: Pfizer and Sandoz, Consultant for: Pfizer and Sandoz, E. J. Kucharz Consultant for: AbbVie, Berlin Chemie, Biogen, Celgene, Egis, Eli Lilly Polska, MSD, Novartis, Pfizer, Polpharma, Roche, Sandoz and UCB Biopharma, G. Babic Employee of: Hexal AG

DOI: 10.1136/annrheumdis-2018-eular.1368 